\title{
Molecular Mapping of High Resistance to Bacterial Leaf Spot in Lettuce PI 358001-1
}

\author{
Yunwen Wang, Huangjun Lu, and Jinguo Hu
}

First and second authors: Everglades Research and Education Center, University of Florida/Institute of Food and Agricultural Sciences, Belle Glade 33430; and third author: United States Department of Agriculture-Agricultural Research Service, Western Regional Plant Introduction Station, Washington State University, Pullman 99164.

Accepted for publication 12 May 2016.

\begin{abstract}
Wang, Y., Lu, H., and Hu, J. 2016. Molecular mapping of high resistance to bacterial leaf spot in lettuce PI 358001-1. Phytopathology 106:1319-1325.

Lettuce (Lactuca sativa $\mathrm{L}$.) is a diploid $(2 \mathrm{n}=18)$ with a genome size of 2,600 Mbp, and belongs to the family Compositae. Bacterial leaf spot (BLS), caused by Xanthomonas campestris pv. vitians, is a major disease of lettuce worldwide. Leaf lettuce PI 358001-1 has been characterized as an accession highly resistant to BLS and has white seed. In order to understand inheritance of the high resistance in this germplasm line, an $\mathrm{F}_{3}$ population consisting of 163 families was developed from the cross PI 358001-1 $\times$ 'Tall Guzmaine' (a susceptible Romaine lettuce variety with black seed). The segregation ratio of reaction to disease by seedling inoculation with $X$. campestris pv. vitians $\mathrm{L} 7$ strain in the $\mathrm{F}_{3}$ families was shown to be $32: 82: 48$ homozygous resistant/heterozygous/homozygous susceptible, fitting to $1: 2: 1$

( $n=162, \chi^{2}=3.19, P=0.20$ ). The segregation ratio of seed color by checking $\mathrm{F}_{2}$ plants was 122:41 black/white, fitting to $3: 1\left(n=163, \chi^{2}=0.002\right.$, $P=0.96$ ). The results indicated that both BLS resistance and seed color were inherited as a dominant gene mode. A genetic linkage map based on 124 randomly selected $\mathrm{F}_{2}$ plants was developed to enable molecular mapping of the BLS resistance and the seed color trait. In total, 199 markers, comprising 176 amplified fragment length polymorphisms, 16 simple-sequence repeats, 5 resistant gene candidate markers, and 2 cleaved amplified polymorphic sequences (CAPS) markers were assigned to six linkage groups. The dominant resistance gene to BLS $(X c v r)$ was mapped on linkage group 2 and the gene locus $y$ for seed color was identified on linkage group 5. Due to the nature of a single gene inheritance, the high-resistance gene should be readily transferred to adapted lettuce cultivars to battle against the devastating disease of lettuce.
\end{abstract}

Lettuce (Lactuca sativa $\mathrm{L}$.) is a self-pollinated diploid $(2 \mathrm{n}=18)$ vegetable species with a genome size of $2,600 \mathrm{Mbp}$, and belongs to the family Compositae. Seven horticultural types, including crisphead, butterhead, romaine (cos), leaf, Latin, stem, and oilseed, are widely recognized in lettuce cultivars (Simko 2013). It is the most popular leafy vegetable in many countries, and the total world production was 24.9 million tons on 1.15 million ha in 2013 (FAOSTAT 2015). China is the largest production country for lettuce in the world, and produced approximately $36.9 \%$ of the total, followed by the United States (16.7\%), Spain (3.9\%), Italy (3.7\%), and India (3.3\%) (FAOSTAT 2015). From 10 years of data (2003 through 2013), the global harvested area of lettuce increased by $1.38 \%$ and total production increased by $1.59 \%$ annually worldwide (FAOSTAT 2015). In the United States, lettuce is one of the top 10 most valuable crops, with an annual economic value of over \$2 billion (USDA 2014). Head (crisphead and butterhead, 55.0\% of the lettuce production), romaine $(30.7 \%)$, and leaf $(14.3 \%)$ are the major market types in this country (USDA 2014).

Bacterial leaf spot (BLS) is an economically important disease of lettuce. This disease is caused by Xanthomonas campestris pv. vitians. It was first reported in South Carolina and Virginia in the United States in 1918 (Brown 1918). Because there are no chemicals or cultural methods for control of the disease, use of host plant resistance is the only effective way to combat the disease. The majority of crisphead and romaine lettuce accessions tested thus far have been found to be susceptible (Lu and Raid 2013; Lu et al. 2014; Pernezny et al. 2000; Wang et al. 2015). However, two Latin

Corresponding authors: H. Lu; E-mail address: hjlu@ufl.edu and Y. Wang; E-mail address: ywwang@ufl.edu

http://dx.doi.org/10.1094/PHYTO-09-15-0238-R

(C) 2016 The American Phytopathological Society horticultural-type cultivars ('Little Gem' and 'Pavane'), and a Batavia-type cultivar ('La Brillante') were shown to have resistance by being challenged with California $X$. campestris pv. vitians strains in California (Bull et al. 2007). A highly resistant leaf lettuce genotype (PI 358001-1) was identified against $X$. campestris pv. vitians strain L7 in Florida, and this genotype has much stronger BLS resistance than the well-known resistant Little Gem (Lu and Raid 2013; Lu et al. 2014; Wang et al. 2015). All of these resistant germplasms will provide desirable sources for development of resistant cultivars and investigation of the genetics of host resistance to BLS in lettuce.

Recent investigation reported that the resistance in Little Gem, La Brillante, and Pavane each followed a single dominant gene inheritance, and they may be the same gene or separate but closely linked genes (Hayes et al. 2014). The resistance gene in La Brillante (Xarl) was already mapped to lettuce linkage group (LG) 2 in the 'Salinas 88' $\times$ La Brillante population (Hayes et al. 2014). Using association mapping between a total of 179 lettuce accessions and 350 expressed-sequence tag (EST)-derived single-nucleotide polymorphism (SNP) markers, Lu et al. (2014) found that one SNP (QGB19C20.yg-1OP5) on LG2 and two SNP (Contig 15389-1-OP1 and Contig 603919-OP1) on LG4 were associated with the BLS resistance in PI 358001-1. However, the inheritance mode and the chromosomal location of resistance in this lettuce genotype are as yet unknown.

Seed color was among the traits that were first analyzed for inheritance in lettuce. Two major genes ( $W$ and $Y$ ) were identified to control the seed color in lettuce in early studies (Durst 1929; Thompson 1943). Later, three gene loci for brown seed ( $b r)$, yellow seed $(y)$, and white seed ( $w$ ) were reported (Waycott et al. 1999). Of the three loci, $w$ was mapped on lettuce LG7 (Chen 2005; Kwon et al. 2013; Truco et al. 2007; Simko 2013; Simko et al. 2013) and $y$ was mapped on LG2 (Chen 2005; Waycott et al. 1999). Although the locus $b r$ was assigned to an LG, it has never been assigned to any chromosome of lettuce (Waycott et al. 1999). 
Due to the economic importance of BLS in lettuce production worldwide, it is highly desirable to understand the genetics of the high resistance present in PI 358001-1. The primary objective of this study was to investigate inheritance of BLS resistance in PI 358001-1 and to map the resistance with molecular markers. Additionally, it is also interesting to know of any new chromosomal location of a gene responsible for seed color in lettuce.

\section{MATERIALS AND METHODS}

Plant materials. An $\mathrm{F}_{2}$ segregating population with 163 plants was generated from a cross between $L$. sativa accession PI 358001-1, a leaf lettuce resistant to BLS and having white seed, and L. sativa 'Tall Guzmaine', a romaine lettuce susceptible to BLS and having black seed. $\mathrm{F}_{3}$ families were derived by self-pollination from each of the $163 \mathrm{~F}_{2}$ plants, and seed color (black versus white) was recorded when seed were harvested from the $F_{2}$ plants. Except for one $F_{3}$ family without enough plants, $162 \mathrm{~F}_{3}$ families were tested for resistance to BLS. Then, $124 \mathrm{~F}_{2}$ individuals were randomly chosen for genotyping.

Genomic DNA extraction. Healthy leaf tissues were collected from individual $\mathrm{F}_{2}$ plants at the 7 -week stage and immediately stored in a freezer at $-80^{\circ} \mathrm{C}$. Genomic DNA was extracted from frozen leaves using the cetyltrimethylammonium bromide method of Doyle and Doyle (1990), with minor modifications as described by Liu and $\mathrm{Wu}$ (2012). The DNA quantity and quality were measured by an ND1000 spectrophotometer (NanoDrop Products, Wilmington, DE) and $1.0 \%$ agarose gel electrophoresis, respectively.

Amplified fragment length polymorphism marker assay. A final concentration of the genomic DNA was diluted to $125 \mathrm{ng} \mathrm{\mu l}^{-1}$. The amplified fragment length polymorphism (AFLP) procedure was performed using the IRDye Fluorescent AFLP Kit (LI-COR
Biosciences, Lincoln, NE) following the manufacturer's instructions. In total, 64 three-nucleotide selective primer combinations of restriction enzyme EcoRI/MseI were employed (Table 1). AFLP fragments were detected using $6.5 \%$ polyacrylamide gels with a LI-COR 4300 DNA Analyzer (LI-COR Biosciences). The size of a clear AFLP marker was visually scored using Saga software (version 3.3; LI-COR Biosciences). AFLP markers were designated according to Standard List for AFLP Primer Nomenclature (KeyGene, Wageningen, The Netherlands) followed by the marker size.

Simple-sequence repeat marker assay. Genomic DNA concentration was diluted to $75 \mathrm{ng}^{\mathrm{l}^{-1}}$. In all, 45 simple-sequence repeat (SSR) primer pairs, including 33 genomic SSR and 12 EST-SSR which have been anchored on the LG of lettuce, were obtained from Rauscher and Simko (2013) and Simko (2009), respectively. These SSR primer pairs were first tested for polymorphism on the two parent lines. Only 12 SSR primer pairs (10 genomic SSR and 2 EST-SSR) with unique polymorphic alleles were amplified on the $\mathrm{F}_{2}$ mapping population (Table 2). Amplification of SSR was carried out on a Biosystems 2720 thermal cycler (Applied Biosystems, Foster City, CA) in 10.5- $\mu$ l volumes containing the following components: $1.5 \mu$ of template DNA at $75 \mathrm{ng} / \mu \mathrm{l}, 1.34 \mu \mathrm{l}$ each of forward and reverse primers at $1.0 \mu \mathrm{M}, 0.2 \mu \mathrm{l}$ each of dNTP at $10 \mathrm{mM}, 1.6 \mu \mathrm{l}$ of $10 \times$ polymerase chain reaction (PCR) buffer, $0.2 \mu \mathrm{l}$ of IR-M13 forward primer at $1.0 \mu \mathrm{M}, 0.05 \mu \mathrm{l}$ of $\mathrm{Taq}$ enzyme at $50 \mathrm{U} / \mu \mathrm{l}$, and $4.27 \mu \mathrm{l}$ of nuclease-free water. Cycling parameters were $95^{\circ} \mathrm{C}$ for $5 \mathrm{~min}$; followed by 14 cycles of $94^{\circ} \mathrm{C}$ for $20 \mathrm{~s}, 58^{\circ} \mathrm{C}$ for $1 \mathrm{~min}$, and $72^{\circ} \mathrm{C}$ for $30 \mathrm{~s}$; an additional 28 cycles of $94^{\circ} \mathrm{C}$ for $20 \mathrm{~s}, 55^{\circ} \mathrm{C}$ for $1 \mathrm{~min}$, and $72^{\circ} \mathrm{C}$ for $30 \mathrm{~s}$; and a final extension of $72^{\circ} \mathrm{C}$ for 10 min. A 5.0- $\mu$ l Blue Stop Solution $(95 \%$ formamide, $25 \mathrm{mM}$ EDTA, and $2 \%$ bromophenol blue) was added to each PCR tube (total volume $=15.5 \mu \mathrm{l}$ ), mixed thoroughly, spun down, and denatured for $3 \mathrm{~min}$ at $94^{\circ} \mathrm{C}$ in the thermocycler. Detection of SSR amplification products was the same as AFLP analysis.

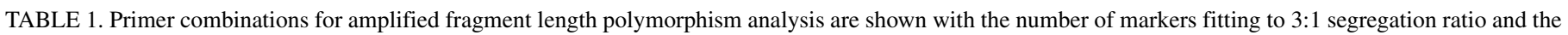
total number of polymorphic markers in parenthesis

\begin{tabular}{|c|c|c|c|c|c|c|c|c|c|}
\hline Primer & M47 CAA & M48 CAC & M49 CAG & M50 CAT & M59 CTA & M60 СТC & M61 CTG & M62 CTT & Total \\
\hline E32 AAC & $0(0)$ & $8(9)$ & $4(4)$ & $0(0)$ & $6(8)$ & $2(4)$ & $4(5)$ & $3(3)$ & $27(33)$ \\
\hline E33 AAG & $0(0)$ & $0(1)$ & $4(7)$ & $2(2)$ & $1(2)$ & $5(5)$ & $2(2)$ & $3(3)$ & $17(22)$ \\
\hline E35 ACA & $3(4)$ & $2(2)$ & $5(8)$ & $0(0)$ & $8(9)$ & 1(1) & $7(8)$ & $2(4)$ & $28(36)$ \\
\hline E36 ACC & 1(1) & $4(6)$ & $3(5)$ & $2(3)$ & $1(1)$ & $2(2)$ & $4(5)$ & $4(4)$ & $21(27)$ \\
\hline E37 ACG & 1(1) & $3(3)$ & $4(9)$ & $2(2)$ & $2(3)$ & $7(7)$ & $1(1)$ & $0(0)$ & $20(26)$ \\
\hline E38 ACT & $0(0)$ & 1(1) & $4(5)$ & $2(2)$ & $2(3)$ & $4(4)$ & $1(2)$ & $3(3)$ & $17(20)$ \\
\hline E40 AGC & $0(0)$ & 1(1) & $2(3)$ & $2(2)$ & $5(5)$ & $0(1)$ & $3(4)$ & $3(3)$ & $16(19)$ \\
\hline E41 AGG & $4(6)$ & $0(0)$ & $7(8)$ & 1(1) & $5(5)$ & $2(2)$ & $9(9)$ & $2(3)$ & $30(34)$ \\
\hline Total & $9(12)$ & $19(23)$ & $33(49)$ & 11(12) & $30(36)$ & $23(26)$ & $31(36)$ & $20(23)$ & $176(217)$ \\
\hline
\end{tabular}

TABLE 2. Information for 10 genomic simple-sequence repeat (SSR) and 6 expressed sequence tag SSR used for linkage mappinga

\begin{tabular}{|c|c|c|c|c|c|}
\hline Marker & Repeat motif & Forward $\left(5^{\prime}-3^{\prime}\right)$ & Reverse $\left(5^{\prime}-3^{\prime}\right)$ & $\begin{array}{l}\text { Fragment } \\
\text { size (bp) }\end{array}$ & $\mathrm{Ta}\left({ }^{\circ} \mathrm{C}\right)^{\mathrm{b}}$ \\
\hline LSSA06-2 & $(\text { TTTTAT })_{3}$ & GCA AGA ATG GTC CCT GTT GT & TGG GTG GGT GTG ATA ATA AGG & 235 & 59 \\
\hline LSSA07 & $(\mathrm{CCA})_{5}$ & AAG ATA CAC ACA ACC ACC CTT G & GGG CAT TTT GCA AAC AGA A & 167 & 59 \\
\hline LSSA12 & $(\mathrm{GT})_{11}$ & TCG AAA ATT TGG AGA GAG TTT CTT & ACA AGG CCC AAT CCT TTT CT & 271 & 61 \\
\hline LSSA14 & $(\mathrm{AG})_{18}$ & TGA GTT GTA GAG CAA CGA GTG C & CAT GGA AGG TCA TAA GTC CCC & 217 & 60 \\
\hline LSSA28-1 & $(\mathrm{GA})_{28}$ & TTC ATC TCT CTC CTC CTT CAG C & ATC CCC ATT GTC CTC CC & 151 & 55 \\
\hline LSSB31 & $(\mathrm{TC})_{14}$ & TTG GTT TGA CCC CTG TTT TC & TCA CAC CCA AGC TGT TGC TA & 307 & 59 \\
\hline LSSB37 & $(\mathrm{TC})_{28}$ & GGT AGG GCA GTC AAG CAA GA & AAT GAT GAT TTT GCC CTT GG & 271 & 59 \\
\hline LSSB40 & $(\mathrm{CT})_{20}$ & TGG TTT TGG TCC CTG TGA TT & GGT CCG ATA TGT GGT GCT CT & 227 & 61 \\
\hline LSSB51 & $(\mathrm{TC})_{20}$ & TCA TTG CGT TTT TGG TC & AAA GGA AGA AGA AGG AGG & 218 & 52 \\
\hline LSSB55-3 & $(\mathrm{AGAGT})_{3}$ & TTA ATT ATA TCC AAA AGA C & CGT ACT GAC GCC CTA CAG GT & 83 & 57 \\
\hline SML-001 & $(\mathrm{CATGAT})_{6}$ & CCA TGG ATC CTG TGT GAA GA & CAC CAT GTT CCA CTT CCA CTT & $196-220$ & $\ldots$ \\
\hline SML-003 & $(\mathrm{GTTTT})_{5}$ & CGG GCT GGT TTT GAT TTT TA & TGT CAA ATC GTC ACG TGG TT & $110-120$ & $\ldots$ \\
\hline BOMZ-ssr & $(\mathrm{CA})_{8}$ & ATA GTA CAG ATT GTT GGT GG & AGA TAT AAC TCC ATT TTC CC & 276 & 50 \\
\hline BOKW-ssr & $(\mathrm{CAT})_{5}$ & GAT TCA ATG AAA GTG ATT GT & ATC AAG AGT ATG TTT GCC TA & 279 & 50 \\
\hline BGTM-ssr & $(\mathrm{GA})_{5}$ & ACA ACT CTA TAA CAA CCG AAC TCC & AAA AAG TCT CTC CAA CAT AAA ACG & 322 & 58 \\
\hline AVMP-ssr & $(\mathrm{AT})_{5}$ & GAT AGG CAA GAA AGT GGA TAA AGA & AAT ATA TGC TGC AAA ACA GGT ATG & 154 & 58 \\
\hline
\end{tabular}

a Markers 1 to 12 were from Rauscher and Simko (2013) and 13 to 16 from van Leeuwen et al. (2010).

b $\mathrm{Ta}=$ annealing temperature. 
Cleaved amplified polymorphic sequences (CAPS) marker assay. Two CAPS markers were developed from two SNP (QGB19C20.yg-1-OP5 and Contig 15389-1-OP1) that had association with BLS resistance in PI 358001-1 (Lu et al. 2014) (Table 3). Two restriction enzymes, $T a q^{\alpha} \mathrm{I}$ and $B s p H I$, were identified for designing CAPS markers for QGB19C20.yg-1-OP5 and Contig 15389-1-OP1 (Kwon et al. 2012), respectively, using NEBcutter V2.0 (New England Biolabs Inc., Ipswich, MA). The enzymes each had only one cutter in the recognition site located on the polymorphic position of SNP. PCR primers were designed by online NCBI/Primer-BLAST (National Center for Biotechnology Information, U.S. National Library of Medicine, Bethesda, MD). The PCR amplification solutions of two CAPS markers were the same as those of SSR markers, and a touchdown PCR procedure was used as follows: an initial denaturation at $95^{\circ} \mathrm{C}$ for $5 \mathrm{~min}$; followed by 5 cycles of $95^{\circ} \mathrm{C}$ for $45 \mathrm{~s}, 68^{\circ} \mathrm{C}$ for $5 \mathrm{~min}$, reduced by $2^{\circ} \mathrm{C}$ per cycle, and $72^{\circ} \mathrm{C}$ for $1 \mathrm{~min}$; denaturation at $95^{\circ} \mathrm{C}$ for $45 \mathrm{~s}, 58^{\circ} \mathrm{C}$ for $2 \mathrm{~min}$, and $72^{\circ} \mathrm{C}$ for $1 \mathrm{~min} ; 95^{\circ} \mathrm{C}$ for $45 \mathrm{~s} ; 56^{\circ} \mathrm{C}$ for $2 \mathrm{~min}$ and $72^{\circ} \mathrm{C}$ for $45 \mathrm{~s}$; then 10 cycles of $95^{\circ} \mathrm{C}$ for $45 \mathrm{~s}, 54^{\circ} \mathrm{C}$ for $2 \mathrm{~min}$, and $72^{\circ} \mathrm{C}$ for $1 \mathrm{~min}$; an additional 23 cycles of $95^{\circ} \mathrm{C}$ for $45 \mathrm{~s}, 58^{\circ} \mathrm{C}$ for $2 \mathrm{~min}$, and $72^{\circ} \mathrm{C}$ for $1 \mathrm{~min}$; and a final extension of $72^{\circ} \mathrm{C}$ for $10 \mathrm{~min}$.

For digestion of the PCR products, reaction mixtures containing $2.0 \mu \mathrm{l}$ of PCR product, $2.0 \mu \mathrm{l}$ of $10 \times$ NEBuffer, and $10 \mathrm{U}$ of enzyme $\left(0.5 \mu \mathrm{l}\right.$ of $\mathrm{Taq}^{\alpha} \mathrm{I}$ or $1.0 \mu \mathrm{l}$ of $\left.B s p \mathrm{HI}\right)$ in a total volume of $20 \mu \mathrm{l}$ were incubated for $14 \mathrm{~h}$ at $65^{\circ} \mathrm{C}\left(\operatorname{Taq}^{\alpha} \mathrm{I}\right)$ and $37^{\circ} \mathrm{C}(B s p \mathrm{HI})$, respectively. Gel visualization of CAP markers was the same as AFLP analysis.

Saturation mapping of the BLS resistance gene region. Based on the initial LG developed by mapping previous AFLP, CAPS, and SSR markers, we identified 96 additional SSR from the mapped sequences which were displayed at 0 to 40 centimorgans (cM) of LG2 on lettuce Affymetrix GeneChip (van Leeuwen et al. 2010). Search parameters selected for SSR Locator V.1 software (da Maia et al. 2008) included 5-di-, tri-, tetra-, 4-penta-, hexa-, 3-hepta-, octa-, nona-, and decanucleotide repeats. All other parameters for SSR searching were set to program defaults. The parameters of the primer design with SSR Locator V.1 software were as follows: the amplicon size was set from 140 to $350 \mathrm{bp}$; GC clamp was set 0 ; the primer size was set from 18 to $22 \mathrm{bp}$, with optimum size of $20 \mathrm{bp}$; the content of $\mathrm{G} / \mathrm{C}$ was set from 45 to 50; both start and end points of a region scanned were set as automatic; and the end stability was set as 250. SSR primers were synthesized by Sigma-Aldrich (The Woodlands, TX). An M13-tagged sequence (CACGACGTTGTAAAACGAC) was added to the 5' end of each forward primer. In addition, 8 resistant gene candidate $(R G C)$ derived markers which have been anchored on lettuce LG2 were obtained from McHale et al. (2009). PCR conditions and product visualization were the same as used in SSR analysis.

BLS resistance evaluation. Tests of resistance to BLS were conducted according to Lu and Raid (2013) and Wang et al. (2015).
The tests were repeated twice. Seed of each $\mathrm{F}_{3}$ family were randomly sown in a single row with 10 rows in a flat tray $(30$ by $50 \mathrm{~cm})$ filled with Fafard growing mix (Sun Gro Horticulture, Agawam, MA). In every other tray, the resistant parent and the susceptible parent were added as two controls. Eight plants of each family were grown on a row. $X$. campestris pv. vitians strain 7 , the most virulent $X$. campestris pv. vitians isolate recovered from the Everglades Agricultural Area in Florida, was used for inoculation. The first replicate was sown on 14 October 2014 and seedlings were inoculated on 21 November 2014. The second replicate was sown on 27 October 27 and seedlings were inoculated on 26 November 2014. All procedures for $X$. campestris pv. vitians inoculum preparation, inoculation, and severity rating were carried out as described by $\mathrm{Lu}$ and Raid (2013) and Wang et al. (2015). Thus, in total, 16 plants were tested for each $\mathrm{F}_{3}$ family. The disease severity of a plant was evaluated using the 0 -to-4 rating system described by Lu and Raid (2013), where $0=$ no symptoms; $1=1$ to 10 lesions, with each diameter less than $3 \mathrm{~mm}$; $2=$ more than 10 lesions, with each diameter less than $3 \mathrm{~mm} ; 3=$ lesions with diameters larger than $3 \mathrm{~mm}$; and $4=$ coalesced lesions. The reaction to disease for a single plant was identified as a resistant type with a score of 0 or 1 for disease severity, and as a susceptible type with a score of higher than 1 .

Seed color investigation. The seed color of PI 358001-1 was white and Tall Guzmaine was black. Black color has been shown to be dominant to white (Durst 1929; Thompson 1943). The seed color of each $\mathrm{F}_{3}$ family was observed visually as homozygous recessive white and dominant black.

Linkage analysis. Segregation ratios for all markers, BLS resistance type, and seed color were analyzed using a $\chi^{2}$ test. Codominant markers, including SSR and CAPS markers, and the BLS reaction types were tested against the 1:2:1 ratio. Dominant markers (AFLP) and seed color trait were tested against the 3:1 ratio. Markers were classified into the distorted type if they were significant at a level of $P<0.05$. A genetic linkage map with molecular markers and two phenotypic traits were constructed using MapMaker/EXP version 3.0b (Lander et al. 1987; Lincoln et al. 1993; Sharma and Kaur 2014). Markers were assigned to LG by increasing the logarithm of odds (LOD) value for grouping in steps of 0.5 LOD units. Determination of LG was based on the stability of groups over different LOD values and consequent grouping of SSR and CAPS anchor markers into independent LG. On the LOD value of 4.0, an additional step was performed with increasing LOD 0.1 unit to split up a large LG at a threshold LOD value of 4.1 because the anchored markers indicated that they belonged to two different LG. Marker orders were determined using the procedure of mapping a slightly larger group described by Lincoln et al. (1993). Kosambi's mapping function was used to calculate map distance in centimorgans. No order was forced during the linkage analysis. A visual map was created using MapChart 2.2 (Voorrips 2002).

TABLE 3. Information for two CAP markers used for linkage mapping

\begin{tabular}{|c|c|c|c|c|c|}
\hline Marker & Contig in LSGermOPA ${ }^{\mathrm{a}}$ & Primer sequence $\left(5^{\prime}-3^{\prime}\right)$ & Restriction enzyme & Fragment size (bp) & $\mathrm{Ta}\left({ }^{\circ} \mathrm{C}\right)^{\mathrm{b}}$ \\
\hline QGB19C20 & QGB19C20.yg-1-OP5 & $\begin{array}{l}\text { F-TAT CAA ACG TAA AGT TGG AGC TTG T } \\
\text { R-CCA AAC ACC TTG TGC ATT GCT }\end{array}$ & $T a q^{\alpha} \mathrm{I}$ incubated at $65^{\circ} \mathrm{C}$ & 90 & $59.24 / 60.20$ \\
\hline Cntg15389 & Contig 15389-1-OP1 & $\begin{array}{l}\text { F-TGA GTG ATA AAA TGG AAG AAA CCC C } \\
\text { R-TGC TTT ATC ATT TCT CTC CAA AGG T }\end{array}$ & $B s p \mathrm{HI}$ incubated at $37^{\circ} \mathrm{C}$ & 90 & $59.29 / 58.75$ \\
\hline
\end{tabular}

a Kwon et al. 2012.

b $\mathrm{Ta}=$ annealing temperature.

TABLE 4. Segregation of reactions to bacterial leaf spot disease (BLS) inoculated by Xanthomonas campestris pv. vitians strain L7 in 162 lettuce $\mathrm{F}_{3}$ families derived from Lactuca sativa acc. PI 358001-1 $\times$ L. sativa Tall Guzmaine

\begin{tabular}{lccccc}
\hline Reaction & Number of $\mathrm{F}_{3}$ families & Homozygous resistant & Heterozygous & Homozygous susceptible & $P$ of $\chi^{2}$ for $1: 2: 1$ ratio \\
\hline Observed & 162 & 32 & 82 & 48 & 0.20 \\
Expected & 162 & 40.5 & 81 & 40.5 & $\ldots$ \\
\hline
\end{tabular}




\section{RESULTS}

BLS disease. The parent PI 358001-1 was used as resistant check and parent Tall Guzmaine as susceptible check for every two trays, with a total of 18 rows planted per replicate. The BLS reaction testing was repeated twice. All plants of PI 358001-1 were identified as resistant, whereas all plants of Tall Guzmaine were susceptible. It assured that successful inoculations were applied in phenotyping. Among $162 \mathrm{~F}_{3}$ families, 32 were homozygous resistant, 82 were heterozygous, and 48 homozygous susceptible, fitting to a 1:2:1 segregation ratio $\left(\chi^{2}=3.19, P=0.20\right)$ (Table 4$)$. The $\mathrm{F}_{2}$ population was previously tested against the L7 strain and the segregation ratio was 3:1 resistant/susceptible (data not shown). Thus, a dominant gene inheritance was confirmed.

Seed color. The seed color of Tall Guzmaine was black and that of PI 358001-1 was white. Of $163 \mathrm{~F}_{3}$ families, the seed color of 122 families was black and the remaining 41 families had white seed. This also fit to a single dominant gene segregation ratio of $3: 1\left(\chi^{2}=\right.$ $0.002, P=0.96$ ) (Table 5).

Molecular linkage map. In total, 240 polymorphic markers, including 217 AFLP, 16 SSR, $5 R G C$, and 2 CAPS, were detected in the mapping population. On average, 3.39 polymorphisms were detected for each AFLP primer combination. Of the first 33 tested genomic SSR markers, 10 (30.3\%) were polymorphic, whereas only 2 polymorphic markers were identified from 12 EST-SSR markers, with a polymorphic rate of $16.7 \%$. During the saturation mapping, 96 additional SSR designed from mapped sequences in the 0- to 40-cM region of LG2 on lettuce Affymetrix GeneChip (van Leeuwen et al. 2010) were screened in this study, and only 4 SSR (4.2\%) were mapped. However, five of eight $R G C$ markers were polymorphic and mapped. Of 217 AFLP, $176(81.1 \%)$ fit to a 3:1 segregation ratio for a dominant marker at $P<0.05$, whereas all SSR and CAPS markers fit to a 1:2:1 ratio for a codominant marker at $P<0.05$. Of these markers that fit the expected ratio, 179 markers were grouped to $11 \mathrm{LG}$, and another 20 markers consisting of 19 AFLP and 1 SSR did not group with other markers. For the $11 \mathrm{LG}, 6$ were assigned to lettuce chromosomal LG based on the anchor markers on the reference maps (McHale et al. 2009; Rauscher and Simko 2013) or association analysis (Lu et al. 2014), and the remaining LG were not assigned, including an LG with 25 AFLP markers and 4 small LG with a few AFLP markers (data not shown) (Table 6). The LG spanned 1,707.3 cM.

In total, 23 anchor markers, including $15 \mathrm{SSR}, 5$ RGC, 2 CAPS, and 1 AFLP were mapped to six LG (Table 6). LG8 and LG9 were

TABLE 5. Segregation of seed color in 163 lettuce $F_{3}$ families derived from Lactuca sativa acc. PI 358001-1 $\times$ L. sativa Tall Guzmaine

\begin{tabular}{lcllc}
\hline Reaction & $\begin{array}{c}\text { Number of } \\
\mathrm{F}_{3} \text { families }\end{array}$ & Black & White & $\begin{array}{c}P \text { of } \chi^{2} \text { for } \\
3: 1 \text { ratio }\end{array}$ \\
\hline Observed & 163 & 122 & 41 & 0.96 \\
Expected & 163 & 122.25 & 40.75 & $\ldots$ \\
\hline
\end{tabular}

each anchored by one SSR marker. LG5 had two anchored SSR markers and LG6 had three anchored SSR markers. LG4 was anchored by one SSR and one CAPS. LG2 was anchored by two SSR (LSSA07 and LSSB37), one CAPS marker (QGB19C20), and one AFLP marker (E41M59_274) during initial map construction (Fig. 1). Because the gene for resistance to BLS was found to locate on LG2 (see below), nine more markers with known chromosomal locations were then added to determine the chromosomal region harboring the resistance gene.

Loci for BLS and seed color. The resistance to BLS in PI 358001-1 was controlled by a dominant gene, Xcvr, that was mapped to LG2 (Fig. 1). Xcvr was found to locate at one end of LG2, with the AFLP marker E32M48_528 being $13.5 \mathrm{cM}$ from the gene. The closest anchor marker (LR0089) mapped at $17.1 \mathrm{cM}$ from Xcvr. Although the CAPS marker derived from QGB19C20.yg-1-OP5 was also mapped to LG2, the genetic distance between this marker and $X c v r$ was $256.6 \mathrm{cM}$ (Fig. 1). The gene for seed color was mapped to LG5 and was flanked by AFLP markers E33M50_360 and E35M61_322 at an interval of $30.2 \mathrm{cM}$ (Fig. 1).

\section{DISCUSSION}

Although a number of molecular markers have been applied to lettuce genetic analysis, AFLP, SSR, and SNP markers are commonly used for construction of a framework linkage map and mapping of genes or quantitative trait loci (QTL) in lettuce. The average AFLP polymorphic rate of 3.39 in this study complied with the previous report that the polymorphism was relatively low in lettuce (van Treuren 2001) but was far less than that detected in the $\mathrm{F}_{2}$ mapping population developed from an interspecific cross (Jeuken et al. 2001; Syed et al. 2006). Jeuken et al. (2001) observed a rate of $81 \%$ for polymorphism between $L$. saligna CGN 11341 and L. sativa Norden. Because only a few AFLP primer combinations were shared with other linkage maps and the polymorphism level was low (Jeuken et al. 2001; Syed et al. 2006), limited AFLP markers were identified as anchor markers between this linkage map and consensus maps. The polymorphic rate for SSR markers in the present study was also lower than that scored from the $\mathrm{F}_{2}$ mapping population developed from an interspecific cross (Rauscher and Simko 2013). The results indicated that the genetic analysis for an intraspecific mapping population demands testing more molecular markers than for an interspecific one. From these 16 SSR markers, only 1 genomic marker, LSSA06 was not mapped to any LG, and 1 genomic marker, LSSA07 was mapped to LG2 instead of LG6 in the consensus map (Rauscher and Simko 2013). LSSA06 and LSSA07 amplified multiple alleles. This may be the reason for disagreement with consensus map. Although an LG with 25 AFLP markers was not assigned with a chromosomal LG due to lack of anchor markers, there were two lettuce LG (LG1 and LG3) which were not identified in this study. The genomic locations of the two target traits (i.e., BLS resistance and seed color) were identified by mapped markers. In particular, the location of the BLS resistance

TABLE 6. Information of linkage groups (LG) of the Lactuca sativa acc. PI 358001-1 $\times$ L. sativa Tall Guzmaine linkage mapa

\begin{tabular}{|c|c|c|c|c|c|c|c|}
\hline LG & $\begin{array}{l}\text { Number of } \\
\text { AFLP markers }\end{array}$ & $\begin{array}{l}\text { Number of } \\
\text { SSR markers }\end{array}$ & Number of $R G C$ & $\begin{array}{c}\text { Number of CAP } \\
\text { markers }\end{array}$ & $\begin{array}{l}\text { Total number of } \\
\text { markers }\end{array}$ & Length of LG (cM) & $\begin{array}{c}\text { Number of anchor } \\
\text { markers }\end{array}$ \\
\hline LG2 & 25 & 6 & 5 & 1 & $37^{\mathrm{b}}$ & 302.2 & 13 \\
\hline LG4 & 12 & 1 & 0 & 1 & 14 & 185.4 & 2 \\
\hline LG6 & 8 & 3 & 0 & 0 & 11 & 120.9 & 3 \\
\hline LG8 & 32 & 1 & 0 & 0 & 33 & 286.7 & 1 \\
\hline LG9 & 28 & 1 & 0 & 0 & 29 & 364.0 & 1 \\
\hline Unknown & 25 & 0 & 0 & 0 & 25 & 212.1 & 0 \\
\hline
\end{tabular}

a Abbreviations: AFLP = amplified fragment length polymorphism, $\mathrm{SSR}=$ simple-sequence repeat, $R G C=$ resistant gene candidate, and $\mathrm{cM}=$ centimorgans.

b A single dominant locus for gene resistant to bacterial leaf spot disease was on LG2.

c A single dominant locus for black seed color was on LG5. 
gene on LG2 was determined by three anchor markers, including one AFLP marker (E41M59-274), one SSR marker (LSSB37), and one CAP marker (QGB19C20), and was then confirmed by adding nine more anchor markers to the region of the resistance gene.

At the present time, a number of genetic linkage maps have been published in lettuce (Atkinson et al. 2013; Hayashi et al. 2008; Jeuken et al. 2001; Kesseli et al. 1994; Landry et al. 1987; Syed et al. 2006; Truco et al. 2007, 2013; Waycott et al. 1999) and a total of 14 map versions are accessible online at http://cgpdb.ucdavis.edu/ GeneticMapViewer/display/. Genomic positions of disease resistance genes and QTL, including Verticillium wilt, turnip mosaic virus, downy mildew, powdery mildew, big vein, Fusarium wilt, and anthracnose, have been mapped on the genetic linkage map of lettuce (Simko 2013). The lettuce chromosome 2 has a resistancegene-rich region that harbors at least nine downy mildew resistance genes (McHale et al. 2009; Simko et al. 2015; Wroblewski et al. 2007), one locus for resistance to root aphid (Ellis et al. 1994), and the BLS resistance gene Xarl in La Brillante (Hayes et al. 2014). The BLS resistance gene Xcvr in PI 358001-1 was also mapped to this region in the present study. It would be interesting to know the relationship between Xarl and Xcvr. The BOMS SNP marker and the AFLP marker E35/M49-189 flanked the Xarl gene at a genetic distance of $15.8 \mathrm{cM}$ in the Salinas $88 \times$ La Brillante population (Hayes et al. 2014). These two markers were $8.2 \mathrm{cM}$ apart from each other in the 'Salinas' $\times$ 'UC96US23' population that has no resistance to BLS (McHale et al. 2009). Neither of these two markers was polymorphic in this mapping population. However, we were able to map the RGC markers LR0089, LR0035, LK0036, and LR0029 and the BOMZ-ssr marker to LG2 (Fig. 1). These five markers were very close to one another, with a cumulative distance of $0.4 \mathrm{cM}$, and were approximately 3.4 to $4.0 \mathrm{cM}$ proximal to the AFLP E32M45_528, the closest marker to the resistance gene. The four $R G C$ markers were also mapped to LG2, with a cumulative distance of $3.8 \mathrm{cM}$ by McHale et al. (2009) and $1.3 \mathrm{cM}$ by Hayes et al. (2014). Although the map orders of the $R G C$ markers were slightly different in these three studies, it was conclusive that the markers were tightly linked to each other and were close to one end of LG2. In the study of Hayes et al. (2014), the marker BOMS cosegregated with LR0029 in the Salinas $\times$ UC96US23 population and Xarl was $1.2 \mathrm{cM}$ proximal to BOMS in the Salinas $88 \times$ La Brillante population. In the present study, all markers were mapped proximally to the gene Xcvr. The closest marker, E32M48_528, was $13.5 \mathrm{cM}$ from $X c v r$ and the $R G C$ markers were at least $17.1 \mathrm{cM}$ from $X c v r$. These comparisons indicate that $X c v r$ and Xarl are different genes for resistance to BLS.

The SNP marker QGB19C20 from LG2 was associated with disease severity in both the Q general linear model and Q + K mixed linear model in a previous study (Lu et al. 2014). The $R^{2}$ value was 0.09 with a $P$ value of 0.0002 in the Q general linear model, and the $R^{2}$ was 0.04 with a $P$ value of 0.02 in the $\mathrm{Q}+\mathrm{K}$ mixed linear model. As expected, the CAPS marker derived from QGB19C20 by using Taq ${ }^{\alpha}$ to digest the SNP site was mapped on LG2 in this study. However, the CAPS marker QGB19C20 was mapped at a significant distance $(256.6 \mathrm{cM})$ from $X c v r$. The disagreement between these two studies was likely due to a false positive in association analysis because false positives are often observed in association studies (Atwell et al. 2010; Lu et al. 2015).

BLS and downy mildew are two major diseases of lettuce. These diseases can occur in the field at the same time or sequentially in the growing season in main production areas of the United States. It is desirable to develop resistant cultivars that combine both BLS resistance and downy mildew resistance. Over $30 \mathrm{Dm}$ genes have been identified in lettuce, and the resistance-gene-rich region of LG2 has been known to harbor 9 such genes in different genetic backgrounds, including Dm1, Dm2, Dm3, Dm6, Dm14, Dm15, Dm16, Dm18, and Dm50 (Simko et al. 2015). The BLS resistance gene Xarl was mapped to this region in a previous study (Hayes et al. 2014). Our study showed that Xcvr is also located in the same region. Because this is a resistance gene hotspot, lettuce breeders should monitor it to know what resistance genes they have in their breeding programs.
LG2

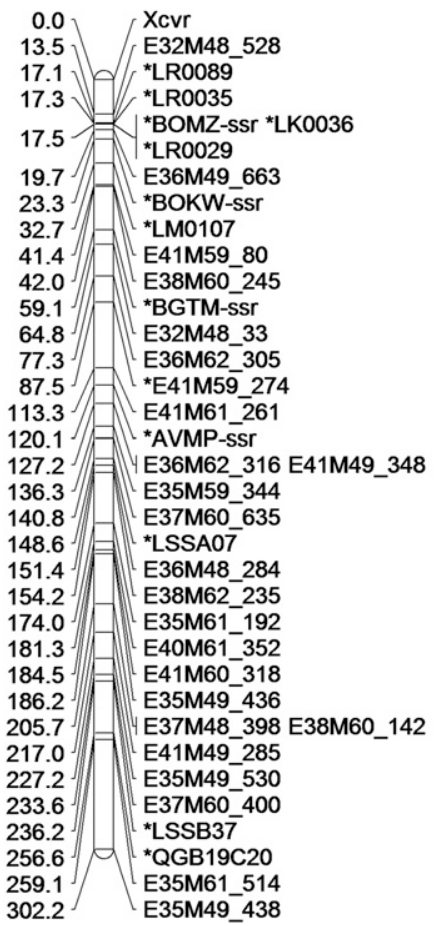

LG5[1]

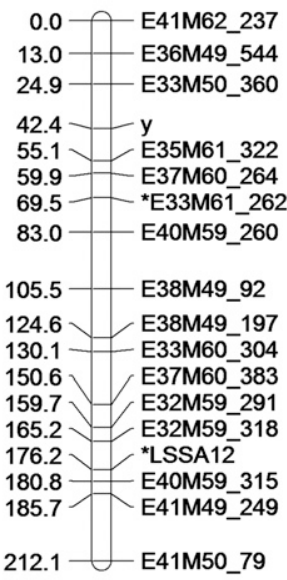

LG5[2]

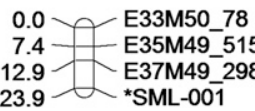

12.9 E37M49_298

23.9 *SML-00

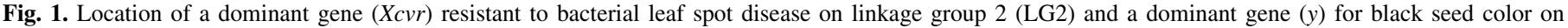
LG5. Genetic distances in Kosambi centimorgans are shown at the left of each LG. Asterisked markers are anchored markers. 
The seed color of lettuce is widely classified as white, black (brown), and yellow types. Classic genetic investigation found that two major genes, $W$ and $Y$, conferred one black phenotype ( $\left.W_{-} Y_{-}\right)$, one yellow phenotype ( $\left.w w Y_{-}\right)$, and two white phenotypes ( $W_{-} y y$ and wwyy) (Durst 1929; Lindqvist 1960; Thompson 1943). Using the RYDER population, three seed color trait loci, including white seed $(w)$, brown seed $(b r)$, and yellow seed $(y)$ were assigned to three different LG with random amplified polymorphic DNA markers, and white seed was considered to have an epistatic effect to brown seed (Waycott et al. 1999). Based on the lettuce integrated map from the RYDER population with six other populations, white seed $(w)$ and yellow seed (y) were mapped to lettuce LG7 and LG2, respectively (Chen 2005; Truco et al. 2007). However, the brown seed ( $b r$ ) trait was never assigned to any chromosomal LG. Now, there are more investigations reporting that seed coat color trait was mapped on lettuce LG7 (Kwon et al. 2013; Simko 2013); however, no evidence confirmed the $y$ locus on LG2. In our study, Tall Guzmaine was homozygous for black seed, and its genotype should be $W W Y Y$, whereas PI 358001-1 was homozygous for white seed, and there was no yellow seed progeny among the $F_{3}$ families; therefore, its genotype should be WWyy. The black seed color trait that has been mapped to LG5 in this study appears to be contributed by the $y$ locus, not $w$. The single gene $(Y)$, jointly with $W$ to confer dominant seed color trait of black to white, was inherited from Tall Guzmaine.

\section{ACKNOWLEDGMENTS}

We thank P. McCord, M. Kanaan, and K. McCorkle at the United States Department of Agriculture (USDA) Agricultural Research Service U.S. Sugar Cane Field Station for providing facilities for DNA quality measurement and sample loading; J. Todd for computer software assistance; and A. Carroll, $\mathrm{Ph} . \mathrm{D}$. student R. Kandel, and internship undergraduate student G. Faroutine for lab and greenhouse assistance. This work was supported by grants from Florida Specialty Crop Block Grant Program, USDA grant number 00114165, and the CRIS project number FLA-BGL-005105 to H. Lu.

\section{LITERATURE CITED}

Atkinson, L. D., McHale, L. K., Truco, M. J., Hilton, H. W., Lynn, J., Schut, J. W., Michelmore, R. W., Hand, P., and Pink, D. A. 2013. An intra-specific linkage map of lettuce (Lactuca sativa) and genetic analysis of postharvest discoloration traits. Theor. Appl. Genet. 126:2737-2752.

Atwell, S., Huang, Y. S., Vilhjálmsson, B. J., Willems, G., Horton, M., Li, Y., Meng, D., Platt, A., Tarone, A. M., Hu, T. T., Jiang, R., Muliyati, N. W., Zhang, X., Amer, M. A., Baxter, I., Brachi, B., Chory, J., Dean, C., Debieu, M., de Meaux. J., Ecker, J. R., Faure, N., Kniskern, J. M., Jones, J. D. G., Michael, T., Nemri, A., Roux, F., Salt, D. E., Tang, C., Todesco, M., Traw, M. B., Weigel, D., Marjoram, P., Borevitz, J. O., Bergelson, J., and Nordborg, M. 2010. Genome-wide association study of 107 phenotypes in Arabidopsis thaliana inbred lines. Nature 465:627-31.

Brown, Z. A. 1918. Some bacterial diseases of lettuce. J. Agric. Res. 13: 367-388.

Bull, C. T., Hayes, R., Madden, L. V., Koike, S. T., and Ryder, E. 2007. Genetic diversity of lettuce for resistance to bacterial leaf spot caused by Xanthomonas campestris pv. vitians. Online publication. Plant Health Prog. doi:10.1094/PHP-2007-0917-02-RS

Chen, F. 2005. Lettuce Genetic Map Viewer Setup. Online publication. University of California, Davis. http://cgpdb.ucdavis.edu/database/genome_viewer/viewer/

da Maia, L. C., Palmieri, D. A., de Souza, V. Q., Kopp, M. M., de Carvalho, F. I. F., and de Oliveira, A. C. 2008. SSR Locator: Tool for Simple Sequence Repeat Discovery Integrated with Primer Design and PCR Simulation. Int. J. Plant Genomics 2008:Article 412696. doi:10.1155/2008/ 412696

Doyle, J. J., and Doyle, J. K. 1990. Isolation of plant DNA from fresh tissue. Focus 12:13-15.

Durst, C. E. 1929. Inheritance in lettuce. Science 69:553-554.

Ellis, P. R., Pink, D. A. C., and Ramsey, A. D. 1994. Inheritance of resistance to lettuce root aphid in the lettuce cultivars 'Avoncrisp' and 'Lakeland'. Ann. Appl. Biol. 124:141-151.

FAOSTAT. 2015. FAOSTAT Domains. Lettuce and chicory. Online publication. http://faostat3.fao.org/browse/Q/QC/E

Hayashi, E., Aoyama, N., and Still, D. W. 2008. Quantitative trait loci associated with lettuce seed germination under different temperature and light environments. Genome 51:928-947.
Hayes, R. J., Trent, M. A., Truco, M. J., Antonise, R., Michelmore, R. W., and Bull, C. T. 2014. The inheritance of resistance to bacterial leaf spot of lettuce caused by Xanthomonas campestris pv. vitians in three lettuce cultivars. Hortic. Res. 1:Article 14066. doi:10.1038/hortres.2014.66

Jeuken, M., Van Wijk, R., Peleman, J., and Lindhout, P. 2001. An integrated interspecific AFLP map of lettuce (Lactuca) based on two L. sativa $\times$ L. saligna $\mathrm{F}_{2}$ populations. Theor. Appl. Genet. 103:638-647.

Kesseli, R. V., Paran, I., and Michelmore, R. W. 1994. Analysis of a detailed genetic linkage map of Lactuca sativa (lettuce) constructed from RFLP and RAPD markers. Genetics 136:1435-1446.

Kwon, S., Simko, I., Hellier, B., Mou, B., and Hu, J. 2013. Genome-wide association of 10 horticultural traits with expressed sequence tag-derived SNP markers in a collection of lettuce lines. Crop J. 1:25-33.

Kwon, S. J., Truco, M. J., and Hu, J. 2012. LSGermOPA, a custom OPA of 384 EST-derived SNPs for high-throughput lettuce (Lactuca sativa L.) germplasm fingerprinting. Mol. Breed. 29:887-901.

Lander, E. S., Green, P., Abrahamson, J., Barlow, A., Daly, M. J., Lincoln, S. E., and Newberg, L. A. 1987. MAPMAKER: An interactive computer package for constructing primary genetic linkage maps of experimental and natural populations. Genomics 1:174-181.

Landry, B. S., Kesseli, R. V., Farrara, B., and Michelmore, R. W. 1987. A genetic map of lettuce (Lactuca sativa $\mathrm{L}$.) with restriction fragment length polymorphism, isozyme, disease resistance and morphological markers. Genetics 116:331-337.

Lincoln, S. E., Daly, M. J., and Lander, E. S. 1993. Constructing genetic linkage maps with MAPMAKER/EXP Version 3.0: A tutorial and reference manual. A Whitehead Institute for Biomedical Research Technical Report, 3rd ed. McGill University, Montreal, Quebec, Canada.

Lindqvist, K. 1960. Inheritance studies in lettuce. Hereditas 46:387-470.

Liu, L. L., and Wu, Y. 2012. Identification of a selfing compatible genotype and mode of inheritance in switchgrass. BioEnergy Res. 5:662-668.

Lu, H., Hu, J., and Kwon, S. J. 2014. Association analysis of bacterial leaf spot resistance and SNP markers derived from expressed sequence tags (ESTs) in lettuce (Lactuca sativa L.). Mol. Breed. 34:997-1006.

Lu, H., and Raid, R. N. 2013. A novel screening method for evaluation of lettuce germplasm for bacterial leaf spot resistance. HortScience 48: $171-174$

Lu, Q., Zhang, M., Niu, X., Wang, S., Xu, Q., Feng, Y., Wang, C., Deng, H., Yuan, X., Yu, H., Wang, Y., and Wei, X. 2015. Genetic variation and association mapping for 12 agronomic traits in indica rice. BMC Genomics 16:1067.

McHale, L. K., Truco, M. J., Kozik, A., Wroblewski, T., Ochoa, O. E., Lahre, K. A., Knapp, S. J., and Michelmore, R. W. 2009. The genomic architecture of disease resistance in lettuce. Theor. Appl. Genet. 118:565-580.

Pernezny, K., Raid, R. N., and Collins, J. 2000. Cultivar resistance and seed treatment for management of bacterial leaf spot of lettuce. EREC Research Report EV-2000-2, University of Florida/IFAS, Belle Glade, FL.

Rauscher, G., and Simko, I. 2013. Development of genomic SSR markers for fingerprinting lettuce (Lactuca sativa L.) cultivars and mapping genes. BMC Plant Biol. 13:11.

Sharma, N., and Kaur, R. 2014. MAPMAKER/EXP Version 3.0 b: Though used since time immemorial still difficult for beginners to start with map construction for the genetic studies. J. Transl. Proteomics Res. 1: $17-27$.

Simko, I. 2009. Development of EST-SSR markers for the study of population structure in lettuce (Lactuca sativa L.). J. Hered. 100:256-262.

Simko, I. 2013. Marker-assisted selection for disease resistance in lettuce. Pages 267-289 in: Translational Genomics for Crop Breeding, Vol. 1: Biotic Stress. R. K. Varshney and R. Tuberosa, eds. John Wiley \& Sons Ltd., Chichester, UK.

Simko, I., Atallah, A. J., Ochoa, O. E., Antonise, R., Galeano, C. H., Truco, M. J., and Michelmore, R. W. 2013. Identification of QTLs conferring resistance to downy mildew in legacy cultivars of lettuce. Sci. Rep. 3:Article 2875. doi:10.1038/srep02875

Simko, I., Ochoa, O. E., Pel, M. A., Tsuchida, C., Forcada, C. F., Hayes, R. J., Truco, M. J., Antonise, R., Galeano, C. H., and Michelmore, R. W. 2015. Resistance to downy mildew in lettuce 'La Brillante' is conferred by $\mathrm{Dm} 50$ gene and multiple QTL. Phytopathology 105:1220-1228.

Syed, N. H., Sørensen, A. P., Antonise, R., van de Wiel, C., van der Linden, C. G., van 't Westende, W., Hooftman, D. A. P., den Nijs, H. C. M., and Flavell, A. J. 2006. A detailed linkage map of lettuce based on SSAP, AFLP and NBS markers. Theor. Appl. Genet. 112:517-527.

Thompson, R. C. 1943. Inheritance of seed color in Lactuca sativa. J. Agric. Res. 66:441-446.

Truco, M. J., Antonise, R., Lavelle, D., Ochoa, O., Kozik, A., Witsenboer, H., Fort, S. B., Jeuken, M. J. W., Kesseli, R. V., Lindhout, P., Michelmore, R. W., and Pelem, J. 2007. A high-density, integrated genetic linkage map of lettuce (Lactuca spp.). Theor. Appl. Genet. 115:735-746. 
Truco, M. J., Ashrafi, H., Kozik, A., van Leeuwen, H., Bowers, J., Wo, S. R. C., Stoffel, K., Xu, H., Hill, T., Van Deynze, A., and Michelmore, R. W. 2013. An ultra-high-density, transcript-based, genetic map of lettuce. G3 (Bethesda) 3:617-631.

USDA. 2014. USDA-National Agricultural Statistics Service Homepage. https://www.nass.usda.gov

van Leeuwen, H., Ashrafi, H., and Reyes Chin-Wo, S. 2010. Lettuce SFP Chip Project. Online publication. University of California, Davis. http://chiplett. ucdavis.edu/index.php

van Treuren, R. 2001. Efficiency of reduced primer selectivity and bulked DNA analysis for the rapid detection of AFLP polymorphisms in a range of crop species. Euphytica 117:27-37.
Voorrips, R. E. 2002. MapChart: Software for the graphical presentation of linkage maps and QTLs. J. Hered. 93:77-78.

Wang, Y., Lu, H., Raid, R. N., Nuessly, G. S., and Faroutine, G. 2015. Diverse responses of lettuce cultivars and germplasm lines to infections of three isolates of Xanthomonas campestris pv. vitians. HortScience 50:650-655.

Waycott, W., Fort, S. B., Ryder, E. J., and Michelmore, R. W. 1999. Mapping morphological genes relative to molecular markers in lettuce (Lactuca sativa $\mathrm{L}$.). Heredity 82:245-251.

Wroblewski, T., Piskurewicz, U., Tomczak, A., Ochoa, O., and Michelmore, R. W. 2007. Silencing of the major family of NBS-LRR-encoding genes in lettuce results in the loss of multiple resistance specificities. Plant J. 51: 803-818. 